\title{
REKAYASA SISTEM INFORMASI MANAJEMEN PERAWATAN MESIN PERKAKAS DI LABORATORIUM PROSES MANUFAKTUR JURUSAN TEKNIK MESIN UNIVERSITAS BRAWIJAYA
}

\author{
Rusdin ${ }^{1}$, Purnomo Budi Santoso ${ }^{2}$, Djarot B. Darmadi² \\ ${ }^{1} J u r u s a n$ Teknik Perawatan dan Perbaikan mesin Politeknik Negeri Fakfak \\ 2Jurusan Teknik mesin Universitas Brawijaya Malang, JI. MT haryono, 167. Malang-Indonesia \\ Telp : +62-341-554291, 587711, Fax : +62-341-554291 \\ E-mail :_rusdinchicilia@yahoo.co.id
}

\begin{abstract}
Manufacturing Process Laboratory of Mechanical Engineering of University Brawijaya still applies manual system in carrying out preventive maintenance. This has caused delays of action for machine maintenance and difficulties encountered by the manager or head of the laboratory with accessing to data on preventive maintenance matters to obtain required information. Besides, there has been no encoding on the machines, components, and spare parts so that the search for information on the machines and spare parts took a long time. Therefore, a Maintenance Management Information System, which integrates Database science, Preventive maintenance, and machine tools, was created where the steps included developing the prototype. The instrument used in creating the information system was Microsoft Access 2016. Based on the testing results, the Maintenance Management Information System could generate report recaps, daily reports, warnings of available spare parts stocks, and tools and search menu. Accordingly, the information system could meaningfully assist the head of laboratory in managing the maintenance of machines.
\end{abstract}

Keywords: Management information system, machines, preventive maintenance, database.

\section{PENDAHULUAN}

Divisi perawatan wajib memelihara kesiapan setiap mesin agar selalu siap digunakan untuk menunjang kelancaran praktikum. Kegiatan perawatan merupakan kombinasi dari setiap tindakan yang dilakukan untuk menjaga suatu barang sesuai standar yang ditentukan [1]. Lobaratorium Proses Produksi Manufaktur memilki beberapa kekurangan karena sistem perawatan tergantung pada pihak eksternal maintenance bukan oleh internal maintenance. Proses perawatan belum dikategorikan berdasarkan preventive maintenance, routine maintenance dan curative maintenance, sehingga sistem perawatan tidak memiliki perencanaan yang baik [2-6].

Perbaikan prefentif pada mesin mekanik berjalan efektif, dengan indikator sering terjadi keterlambatan perbaikan dari jadwal yang sudah ditetapkan. Data-data yang menunjukkan perbedaan tanggal perencanaan dan tanggal tindakan aktual perawatan mesin di lantai produksi Laboratorium Proses Manufaktur yang dilakukan pada minggu 1 , periode agustus 2016.

Tabel 1. Tanggal Perencanaan dan Tanggal Aktual Perawatan Mesin

\begin{tabular}{|c|c|c|c|}
\hline $\begin{array}{l}\text { Jenis } \\
\text { Mesin }\end{array}$ & kegiatan & $\begin{array}{c}\text { Rencana } \\
\text { Perawata } \\
\mathbf{n}\end{array}$ & $\begin{array}{c}\text { Tanggal } \\
\text { Perawata } \\
\mathbf{n}\end{array}$ \\
\hline $\begin{array}{c}\text { Mesin } \\
\text { Bubut } \\
\text { Type KW } \\
15-486\end{array}$ & $\begin{array}{c}\text { Penggantian } \\
\text { oli } \\
\text { pelumas } \\
\text { Gearbox }\end{array}$ & $\begin{array}{c}7 \text { Agustus } \\
2016\end{array}$ & $\begin{array}{c}15 \\
\text { Agustus } \\
2016\end{array}$ \\
\hline $\begin{array}{c}\text { Mesin } \\
\text { Bubut } \\
\text { Type } \\
\text { C6232 A }\end{array}$ & $\begin{array}{l}\text { Pengantian } \\
\text { oli Eretan } \\
\text { (carriage) } \\
\text { Mesin Bubut }\end{array}$ & $\begin{array}{c}15 \\
\text { Agustus } \\
2016\end{array}$ & $\begin{array}{c}15 \\
\text { Agustus } \\
2016\end{array}$ \\
\hline $\begin{array}{l}\text { Mesin } \\
\text { Milling } \\
\text { Type } \\
\text { X6328B }\end{array}$ & $\begin{array}{c}\text { Penggantian } \\
\text { sabuk } \\
\text { V-Belts }\end{array}$ & $\begin{array}{c}12 \\
\text { Agustus } \\
2016\end{array}$ & $\begin{array}{c}22 \\
\text { Agustus } \\
2016\end{array}$ \\
\hline
\end{tabular}

Dari Tabel 1 terlihat bahwa ada keterlambatan tindakan perawatan mesin dari 
jadwal yang telah ditetapkan oleh regu teknik. Keterlambatan perawatan mesin yang terjadi dapat mengganggu kinerja sebuah mesin. Kondisi terpuruk yang mungkin saja terjadi adalah mengakibatkan mesin shutdown secara tiba-tiba. Kondisi tersebut tentunya dapat merugikan sebuah mesin karena dapat menghambat proses praktikum dan produksi, sehingga mahasiswa atau produksi yang telah ditentukan tidak tercapai sesuai jadwal yang telah ditentukan. Penyebab keterlambatan perawatan ini dikarenakan tidak adanya sistem perawatan yang memberikan informasi dengan baik dan sistematis. Kelemahan sistem perawatan dapat diatasi dengan mengitegrasikan beberapa metode seperti: preventive maintenance dan database. Preventive maintenance merupakan salah satu dari jenis perawatan yang pasti dilakukan perusahaan-perusahaan manufaktur. Menurut Supandi, Preventive maintenance adalah suatu pekerjaan perawatan yang bertujuan untuk mencegah terjadinya kerusakan, atau cara perawatan yang direncanakan untuk pencegahan [7-9]. Kegiatan Preventive maintenance dapat meliputi perencanaan inspeksi rutin dan pemeliharaan dan menjaga fasilitas agar fasilitas dalam keadaan baik sehingga tidak terjadi kerusakan di waktu yang akan datang. Ruang lingkup perawatan preventif termasuk inspeksi, perbaikan kecil, pelumasan dan penyetelan, sehingga peralatan atau mesin-mesin selama beroperasi terhindar dari kerusakan. Database atau basis data adalah suatu kumpulan data yang disusun dalam bentuk tabel-tabel yang saling berkaitan maupun berdiri sendiri dan disimpan secara bersama-sama pada suatu media sehingga mudah untuk digunakan ataupun ditampilkan kembali, serta dapat digunakan melalui banyak program aplikasi secara optimal [10-16]. Database - Preventive maintenance, akan diintegrasikan dan dikemas kedalam software microsoft access 2016 yang disebut SIMPEM (Sistem Informasi Manajemen Perawatan Mesin) di Laboratorium Proses Manufaktur. Dengan adanya SIMPEM, maka aliran data manajemen perawatan mesin dapat diakses kapanpun, lebih cepat, murah, serta mampu menurunkan biaya atas kebutuhan penyimpanan informasi. Penggunaan sistem informasi dapat mempermudah proses pembuatan laporan, pengelolaan infentory, penjadwalan perawatan, alokasi sumberdaya, hingga perhitungan jumlah stock sparepart dan tools. Untuk membangun sistem informasi manajemen perawatan mesin, perlu membangun database dengan file-file antara lain mesin, teknisi, sparepart, dan penjadwalan perawatan mesin. Dengan sistem yang baru, nantinya diharapkan pimpinan lab dan staff akan lebih mudah mengelola laboratoriumnya dari sisi manajemen perwatan mesin.

\section{METODE PENELITIAN}

Metode yang digunakan pada pengembangan SIMPEM adalah merupakan integrasi metode-metode: Preventive Maintenance, Mesin Perkakas, Database dan Sistim Informasi Manajemen.

Preventive Maintenance yaitu untuk mencegah terjadinya kerusakan, atau cara perawatan yang direncanakan untuk pencegahan agar pengobrasian mesin berumur panjang dan mempunyai tiga parameter pekerjaan diantaranya :

a. Inspeksi yaitu inspeksi bagian luar untuk mengamati dan mendeteksi kelainankelainan yang terjadi pada mesin yang sedang beroperasi, misalnya: timbul suara yang tidak normal, getaran, panas, asap dan inspeksi bagian dalam untuk pemeriksaan elemen-elemen mesin yang dipasang pada bagian dalam seperti: roda gigi, ring, paking dan bantalan

b. Pelumasan untuk bagian yang bergerak dan dilaksanakan sesuai dengan standar operasional perawatan tiap mesin

c. Perencanaan dan Penjadwalan sebagai Program perawatan harus dibuat secara lengkap dan teperinci menurut spesifikasi yang diperlukan, seperti adanya perawatan penjadwal mingguan, bulanan, tiap tiga bulan, tiap setengah tahun dan setiap tahun.

Teori Mesin Perkakas menyumbangkan pengetahuan dan data yang lengkap tentang berbagai mesin perkakas yang dimiliki laboratorium.

Database menyimpan tabel-tabel penting diantaranya : 
1. Tabel mesin menyajikan informasi data tentang kode mesin, nama mesin dan jadwal

2. Tabel teknisi memuat identitas teknisi misalnay nama, pendidikan, umur,masa kerja dan pengalaman.

3. Tabel pekerjaan perawatan berisi pekerjaan dan wajib mengisi setiap tabel perawatan pada suatu unit mesin

4. Jadwal merupakan sebagai penunjang kelancaran dalam penyelesaian suatu pekerjaan, menyiapkan susunan pekerjaan, menetapkan waktu dan saat penyelesaian dalam membuat rencana kerja

5. Tabel Peralatan berisikan identitas misalnya nama, tahun, fungsi dan status agar mengetahui jenis peralatan beserta fungsinya

6. Tabel sparepart berisikan identitas diantaranya, jumlah, kualitas, harga, suplayer agar lebih muda pencariannya dan penyimpanan di dalam gudang sparepart.

7. Tabel supplayer untuk menandakan identitasnya diantaranya, nama, alamat, nomor kontak dan nama perusahaan untuk memudahkan menghubunginya jika ada komplain atau ada yang ingin ditanyakan mengenai tentang barang yang dibutuhkan.

8. Tabel bengkel pendukung berisikan identitas diantaranya, nama perusahaan, alamat, keahlian, identitas perusahaan. Bengkel pendukung berfungsi untuk mengerjakan pekerjaan yang tidak bisa dikerjakan dalam laboratorium proses manufaktur karna minimnya peralatan yang berskala industri atau dalam arti mesin yang dibengkel luar lebih diperuntukan untuk mengerjakan order karna mesin mesin yang dimiliki ukurannya besar, lengkap, dan proses pengerjaannya cepat.

Sistem Informasi Manajemen (SIM) berfungsi sebagai pedoman tolak ukur agar Kepala Laboratorium mempermudah mengelola Laboratorium Proses manufaktur. Didalam Laboratorium Proses manufaktur, data - data yang di kelola kedalam Sistem Informasi Manajemen diantaranya, mesin, komponen, sparepart, teknisi/pegawai,jenis kerusakan, peralatan tools dan jenis perawatan dari ke tujuh data - data ini akan di implementasikan kedalam database dan digunakan dengan software sehingga menghasilkan laporan, model matematis dan juga menghasilkan perhitungan untuk membuat keputusan Kepala Laboratorium.

\section{HASIL DAN PEMBAHASAN}

\section{Desain Database}

Pembuatan tahapan software prototypeng mampu menjelaskan langkah desin database yang berfungsi dalam mengidentifikasikan file -file yang diperlukan oleh sisitem informasi yang akan dibangun.

\section{Desain Database Logis}

Desain database logis merupakan desain yang memudahkan pemahaman user bagaimana sistem informasi bekerja secara logika. Desain logis dapat digambarkan dengan menggunakan ERD (Entity Relationship Diagram). Adapun langkah langkah pembuatan ERD salah satunya adalah sebagai berikut :

Tabel 2. Daftar Entitas beserta Atribut

\begin{tabular}{|l|l|}
\hline \multicolumn{1}{|c|}{ Entitas } & \multicolumn{1}{c|}{ Atribut } \\
\hline $\begin{array}{l}\text { Teknisi/ } \\
\text { Pegawai }\end{array}$ & $\begin{array}{l}\text { NIK, Nama, NoHP, Alamat, } \\
\text { Pendidikan, keahlian, TanggalLahir, } \\
\text { TMT. }\end{array}$ \\
\hline Mesin & $\begin{array}{l}\text { Kode Mesin, NamaMesin, Tahun, } \\
\text { Fungsi, Type, Nosery, MerkMesin. }\end{array}$ \\
\hline Komponen & $\begin{array}{l}\text { Kode Komponen, KodeMesin, } \\
\text { NamaKomponen, Tahun, Fungsi, } \\
\text { Kondisi. }\end{array}$ \\
\hline $\begin{array}{l}\text { Jadwal } \\
\text { Perawatan }\end{array}$ & $\begin{array}{l}\text { Kode jadwal Perawatan, } \\
\text { KodeMesin, JenisPerawatan, } \\
\text { NamaKaryawan, TanggalMulai, } \\
\text { tanggalSelesai, Durasi }\end{array}$ \\
\hline $\begin{array}{l}\text { Jenis } \\
\text { Perawatan }\end{array}$ & $\begin{array}{l}\text { Kode Jenis Perawatan, } \\
\text { KodeMesin,KodePerawatan, } \\
\text { TanggalPerawatan, Keterangan, } \\
\text { PenggantianSparepart?. }\end{array}$ \\
\hline Jerusakan \\
Jesin \\
Kerusakan
\end{tabular}


Desain Database Fisik

a). Desain fisik merupakan aktualisasi dari desain logis yang sangat bergantung dengan software yang dipakai. Software yang dipakai pada perancangan sistem ini adalah Microsoft Access 2016. Tabel 3 merupakan salah satu contoh desain database fisik dari entitas mesin pada sistem informasi manajemen perawatan mesin.

Tabel 3. Master Teknisi/Pegawai

\begin{tabular}{|l|l|l|l|l|}
\hline Field & $\begin{array}{l}\text { Data } \\
\text { Type }\end{array}$ & $\begin{array}{l}\text { Field } \\
\text { Size }\end{array}$ & Note & $\begin{array}{l}\text { Primary } \\
\text { Key }\end{array}$ \\
\hline NIK & $\begin{array}{l}\text { Short } \\
\text { Text }\end{array}$ & 6 & NIK & $\checkmark$ \\
\hline Nama & $\begin{array}{l}\text { Short } \\
\text { Text }\end{array}$ & 25 & Nama & - \\
\hline Alamat & $\begin{array}{l}\text { Short } \\
\text { Text }\end{array}$ & 50 & Alamat & - \\
\hline No Hp & Number & 12 & No Hp & - \\
\hline Pendidikan & $\begin{array}{l}\text { Short } \\
\text { Text }\end{array}$ & 25 & Pendidikan & - \\
\hline Keahlian & $\begin{array}{l}\text { Short } \\
\text { Text }\end{array}$ & 40 & Keahlian & - \\
\hline TGL Lahir & $\begin{array}{l}\text { Date/ } \\
\text { Time }\end{array}$ & 15 & TGL Lahir & - \\
\hline TMT & $\begin{array}{l}\text { Short } \\
\text { Text }\end{array}$ & 50 & TMT & - \\
\hline
\end{tabular}

b). Desain fisik entitas mesin

Desain user interface ini bertujuan untuk membuat rancangan dari tampilan sistem yang nantinya akan berinteraksi langsung dengan user. Desain UI meliputi hierarki menu utama, form dan report. Pada sistem informasi manajemen perawatan mesin terdapat satu menu berupa sistem login. Berikut gambar salah satu implementasi hirarki menu utama pada system informasi.

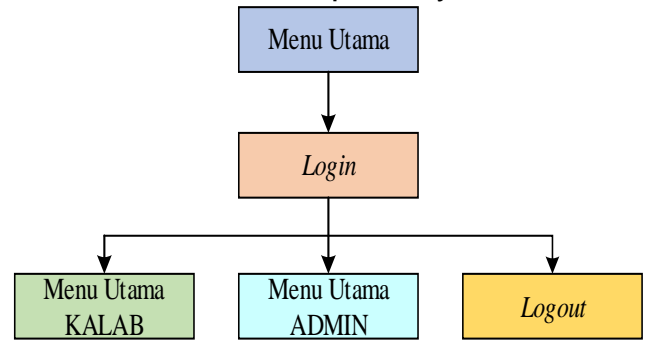

Gambar 1. Hirarki menu Utama

Berdasarkan Gambar 1. menjelaskan bahwa terdapat satu form yang dituju setelah melakukan login, user akan masuk kedalam form sistem informasi, dengan pembatasan hak access sesuai dengan bagian masing masing.

c) Berikut ini merupakan form hirarki menu yang terdapat pada menu utama setelah melakukan login diantaranya, Menu login, master data terdapat data mesin, komponen, jenis kerusakan, jenis perawatan, teknisi, tools dan sparepart. Menu transaksi didalamnya terdapat kerusakan mesin, jadwal perawatan, inventori sparepart, inventori tools dan suplier. Menu pencarian didalamnya mesin, teknisi, tools dan sparepart. Terakhir adalah menu report didalamnya terdapat jadwal perawatan, jenis kerusakan, jenis perawatan, kerusakan mesin, komponen, mesin, sparepart, teknisi dan tools. Ini adalah implementasi dari desain hierarki menu sistem informasi manajemen perawatan mesin :

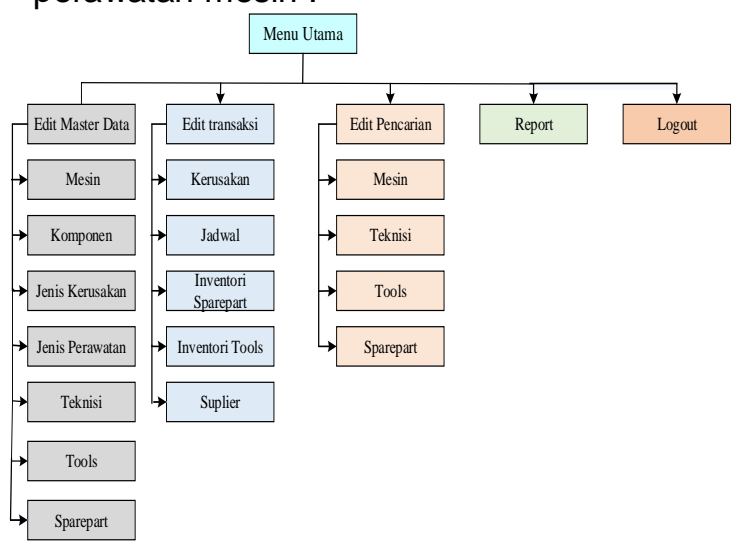

Gambar 2. Desain Hierarki Menu Sistem Informasi Manajemen Perawatan

Desain User Interface Form

a). Menu yang dapat digunakan user sesuai dengan jabatan dan fungsi masingmasing form, yaitu:

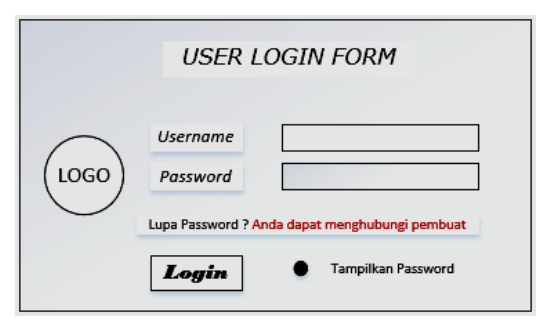

Gambar 3. Desain Menu Login 
Gambar diatas merupakan menu login berfungsi untuk memasukkan username dan password yang dimiliki oleh masing - masing bagian. Form login dibuat sebagai sistem keamanan pertama sebelum masuk kedalam sistem. Form ini berguna sebagai pintu masuk kedalam sistem, yang juga merupakan pembatasan hak akses tiap bagian terhadap sistem. Desain Form Menu Sistem Informasi Menu sistem informasi untuk setiap bagian menu memiliki desain yang sama, yang membedakan adalah pilihan menu didalam tab menu yang dapat diakses di dalam sistem informasi. Dibawah ini merupakan salah satu implementasi desain form untuk menu kalab, sistem informasi adalah sebagai berikut :

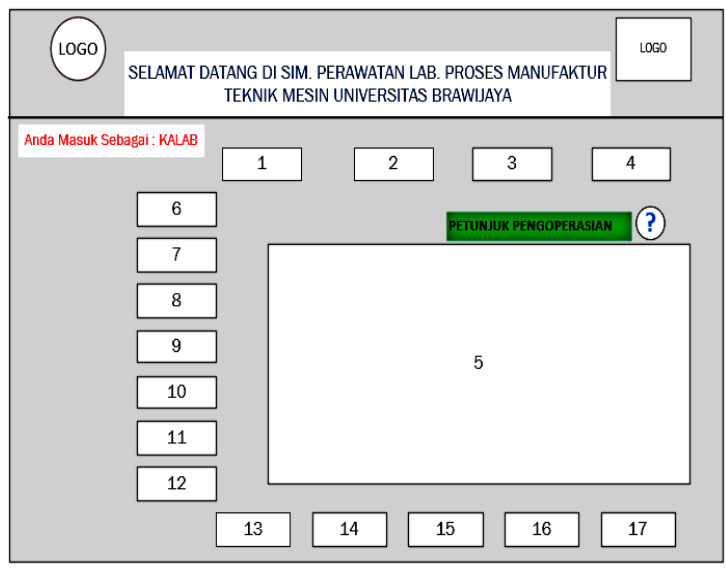

Gambar 4. Desain Form Kalab

Keterangan :
1. Master data
11. Teknisi
2.Transaksi
3. Pencarian
4. Report
5. Logout
6. Display
7. Mesin
8. Komponen
9. Jenis kerusakan
12. Tools
13. Sparepart
14. Data sebelumnya
15. Data selanjutnya
16. Tambah data baru
17. Simpan data
18. Data tabular
19. Report

10.Jenis perawatan

\section{Implementasi}

Tahap implementasi database merupakan upaya untuk membangun basis data fisik yang ditempatkan dalam media penyimpanan dengan bantuan DBMS (Database management System). Perancangan database sistem informasi manajemen perawatan mesin kali ini alat DBMS yang digunakan adalah
Microsoft Access 2016. Untuk memulai perancangan database manajemen sistem maka awal pembuatan yaitu pembuatan tabel dan penentuan relasi. Pembuatan implemetasi database dengan menggunakan Microsoft Access 2016 dapat dilakukan dengan cara sebagai berikut :

a). Implementasi database

1. Buka Microsoft Access 2016 dan pilih Blank desktop database

2. Selanjutnya pilih Create $\rightarrow$ Tabel Design

3. Isi field name dengan judul kolom yang dan data type dengan tipe data pada kolom tersebut.

4. Pilih Save dan memberi nama tabel

5. Databse suda terbentuk secara otomatis dengan tabel yang dibuat.

Berikut dibawah ini tampilan tabel design pada Microsoft Access 2016 :

Tabel 4. Tampilan Design Pada Microsoft Access 2016

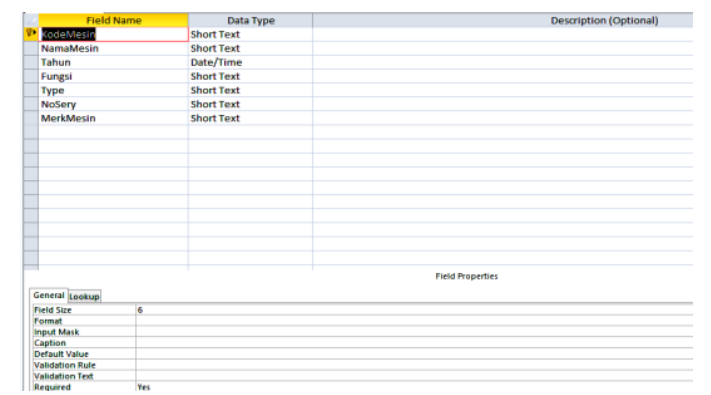

Tabel 4 merupakan implentasi awal langkah pembuatan database dengan menggunakan Microsoft Access 2016. Sehingga didapatkan hasil tabel untuk membuat prototype sistem informasi manajemen perawatan mesin. Kemudian dibawah ini adalah salah satu implementasi tabel yang terdapat dalam sistem informasi manajemen perawatan mesin :

Tabel 5. Tampilan Tabel Mesin

\begin{tabular}{|c|c|c|c|c|c|}
\hline KodeME . & NamaMesin & Tahun & Fungsi & Type & NoSery \\
\hline MBR001 & Mesin Bor Tiang & 02 Maret 199 & 90 Mengebor & TBMI & NR36133104 \\
\hline MBR002 & Mesin Bor Tiang & 29 Agustus 199 & 90 Mengebor & LC-30A & $13 F 0877$ \\
\hline MBR003 & Mesin Bor Tiang & 29 Oktober 199 & 0 Mengebor & KW 1.1 SBM3 & 36200186 \\
\hline MBR004 & Mesin Bor Tiang & 18 November 199 & 90 Mengebor & TBMI KW 063 & 36133104 \\
\hline МВт001 & Mesin Bubut & 01 Maret 201 & 10 Membubut & KW 15-60A & 110405 \\
\hline МВТ002 & Mesin Bubut & 09 September 201 & 11 Membubut & KW 15-604 & 110902 \\
\hline МВТ003 & Mesin Bubut & 09 September 197 & 79 Membubut & CY-1000GF & 9284 \\
\hline МBT004 & Mesin Bubut & 05 Juli 1978 & 78 Membubut & SY-GF2000A & MFG.5180 \\
\hline MBT005 & Mesin Bubut & 05 Juli 1978 & $78 \mathrm{memb}$ & 4-C6232A & MFG.5181 \\
\hline МВТ006 & Mesin Bubut & 12 September 2012 & 12 Membubut & KW-485 & 102117 \\
\hline
\end{tabular}


Tabel 5 merupakan hasil implemetasi tabel mesin yang ada didalam sistem informasi, didalamnya terdapat kode mesin, nama mesin, tahun, fungsi, type, no sery dan merk.

b). Implemetasi Form dan Laporan

Form merupakan sarana yang terdapat dalam microsoft access 2016 yang mempermudah pengguna dalam proses input atau edit data. Selain form, dalam microsoft access juga terdapat report yang berguna untuk membuat ringkasan informasi secara mudah dan berguna untuk pengembalian keputusan. Berikut ini beberapa contoh implementasi form didalam sistem informasi:

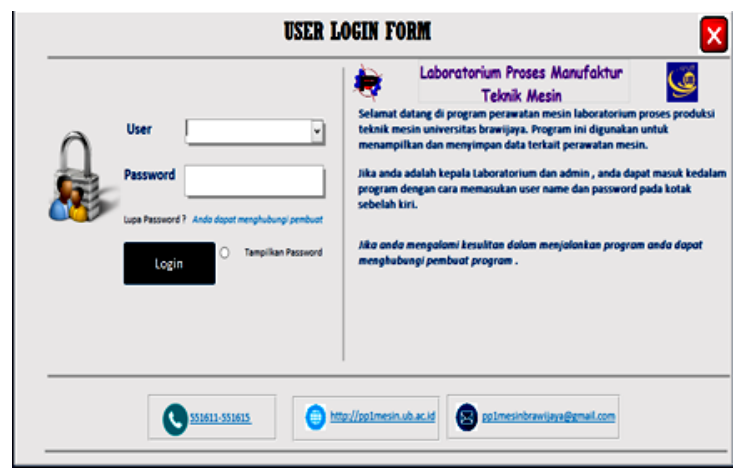

Gambar 5. Menu Form Login

Gambar 5 menunjukkan bahwa ketika pengguna membuka aplikasi,pengguna akan dihadapkan form awal, yang didalamnya terdapat form login dan form login, sesuai dengan username dan passwoed, yang telah dimiliki untuk menggunakan hak aksesnya.

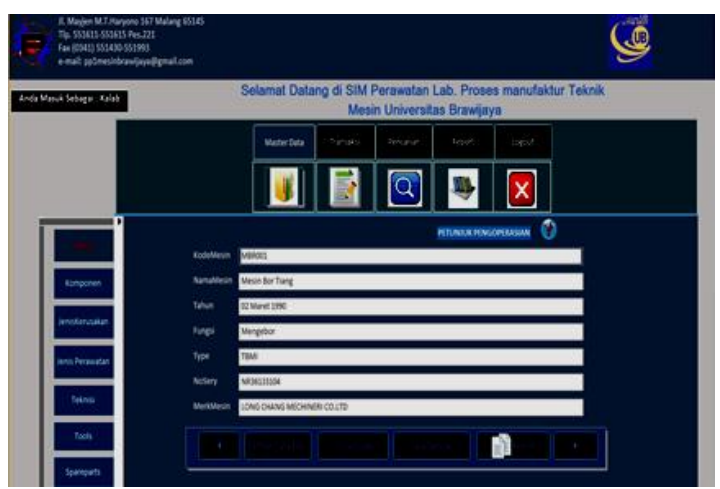

Gambar 6. Implementasi Form Kalab
Berdasarkan gambar 6, terdapat tujuh tab menu pada form Kalab, Kalab dapat memiliki hak akses terhadap semua data yang pada sistem informasi. pada tab menu master data, terdapat menu mesin, komponen, jenis kerusakan, jenis perawatan, teknisi, tools dan sparepart. Pada tab menu transaksi terdapat menu kerusakan mesin, jadwal perawatan, inventori sparepart, inventori tools dan suplayer. Pada tab pencarian, terdapat menu mesin, teknisi, tools dan sparepart. Sedangkan pada menu Report, terdapat menu jadwal perawatan, jenis perawatan, kerusakan mesin, komponen, mesin, sparepart, teknisi, tools.

Form berikutnya adalah form admin (Gambar 7). Pada form ini terdapat tujuh tab menu. Admin memiliki hak akses terhadap semua data yang pada sistem informasi. Pada tab menu master data, terdapat menu mesin, komponen, jenis kerusakan, jenis perawatan, teknisi, tools dan sparepart. Pada tab menu transaksi terdapat menu kerusakan mesin, jadwal perawatan, inventori sparepart, inventori tools dan suplayer. Pada tab pencarian, terdapat menu mesin, teknisi, tools dan sparepart. Sedangkan pada menu Report (Gambar 8), terdapat menu jadwal perawatan, jenis perawatan, kerusakan mesin, komponen, mesin, sparepart, teknisi, tools dan print report. Form ini bisa terkoneksi dengan laporan jadwal perawatan (Gambar 9)

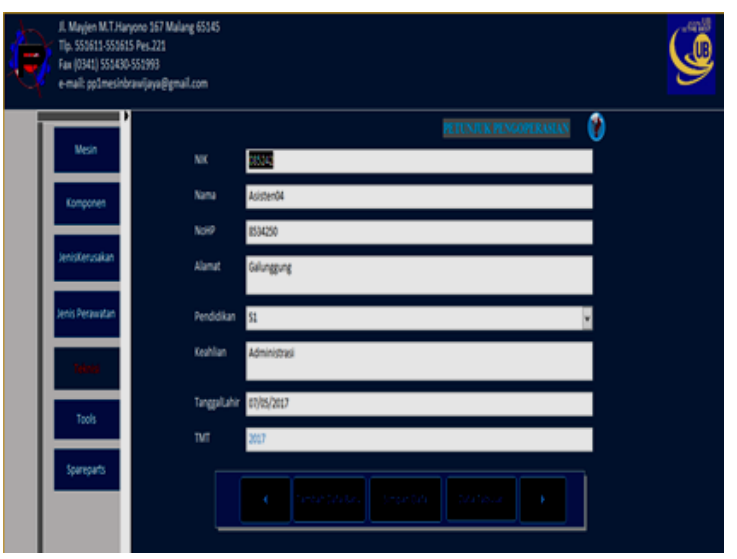

Gambar 7. Menu Form Admin 


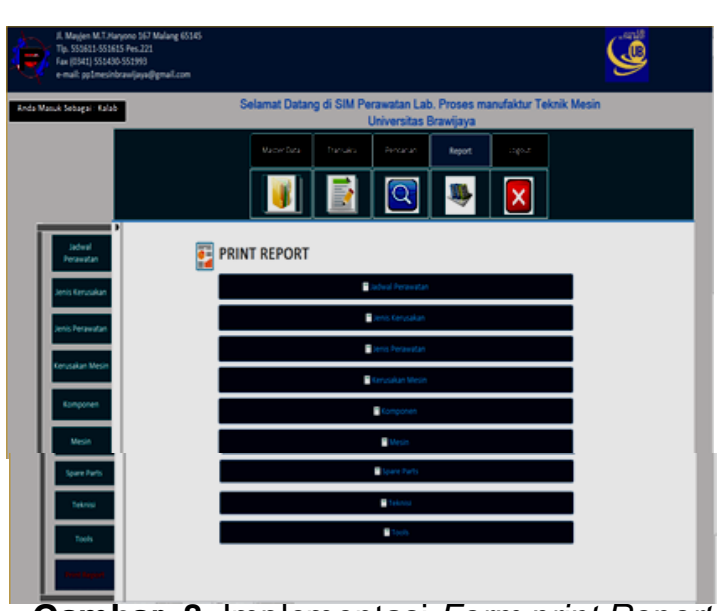

Gambar 8. Implementasi Form print Report

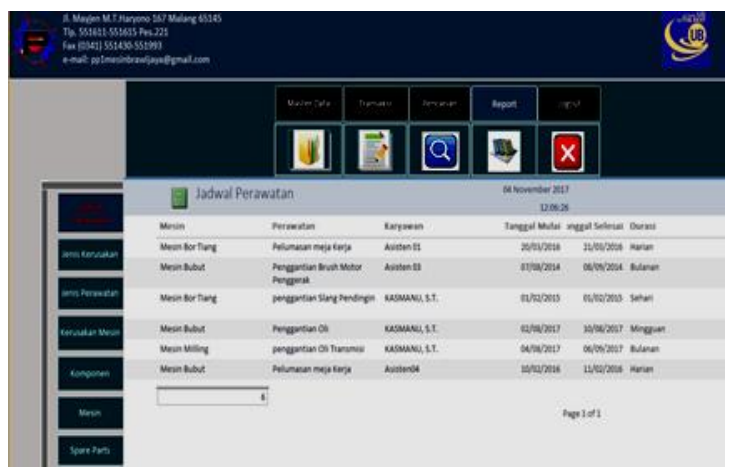

Gambar 9. Laporan Jadwal Perwatan

\section{Pengujian}

Tahap terakhir dalam perancangan sistem adalah melakukan testing atau pengujian terhadap prototype yang telah dibuat. Langkah pengujian penting dilakukan untuk mengetahui apakah prototype yang telah dibuat sesuai dengan harapan atau tidak. Tahap pengujian ditinjau dari tiga sisi, yaitu uji validasi, uji verifikasi, dan uji prototype yang masing masing pengujian memiliki tujuan yang saling berhubungan.

\section{a. Uji Verifikasi}

Verifikasi merupakan proses pemeriksaan desain dan ketelitian antara logika operasional model (program komputer) dengan logika diagram alir. Tujuan dari uji verifikasi adalah untuk menilai apakah progrsm berjalan sesuai dengan yang direncanakan. Hasil uji verifikasi dapat dilihat tabel dibawah ini :
Tabel 6. Uji Verifikasi

\begin{tabular}{|c|c|c|c|}
\hline No. & $\begin{array}{c}\text { Jenis } \\
\text { Pengujian }\end{array}$ & $\begin{array}{c}\text { Proses } \\
\text { Uji }\end{array}$ & Hasil Pengujian \\
\hline 1. & Login & $\begin{array}{l}\text { Memilih } \\
\text { user name } \\
\text { dan } \\
\text { password }\end{array}$ & $\begin{array}{l}\text { Sistem dapat } \\
\text { masuk dan } \\
\text { pengguna dapat } \\
\text { memperoleh } \\
\text { informasi sesuai } \\
\text { dengan hak akses } \\
\text { yang dimiliki }\end{array}$ \\
\hline 2. & Transaksi & $\begin{array}{l}\text { Melakuka } \\
\mathrm{n} \text { input } \\
\text { data ke } \\
\text { dalam } \\
\text { sistem }\end{array}$ & $\begin{array}{l}\text { Sistem dapat } \\
\text { menyimpan } \\
\text { transaksi - } \\
\text { transaksi yang } \\
\text { dilakukan } \\
\text { pengguna. }\end{array}$ \\
\hline 3. & Laporan & $\begin{array}{l}\text { Memilih } \\
\text { jenis } \\
\text { laporan } \\
\text { yang ingin } \\
\text { dilihat } \\
\text { atau di } \\
\text { cetak }\end{array}$ & $\begin{array}{l}\text { Sistem dapat } \\
\text { menampilkan } \\
\text { laporan yang ingin } \\
\text { dilihat }\end{array}$ \\
\hline 4. & Pencarian & $\begin{array}{l}\text { Memasuk } \\
\text { kan kode } \\
\text { pencarian }\end{array}$ & $\begin{array}{l}\text { Sistem dapat } \\
\text { menampilkan data } \\
\text { sesuai dengan } \\
\text { kode yang } \\
\text { dimasukkan } \\
\text { pengguna }\end{array}$ \\
\hline 5. & Keluar & $\begin{array}{l}\text { Menekan } \\
\text { tombol " } \\
\text { Logout" }\end{array}$ & $\begin{array}{l}\text { Sistem dapat } \\
\text { kembali ke menu } \\
\text { utama }\end{array}$ \\
\hline
\end{tabular}

1) Login

Langkah pengujian untuk login adalah dengan cara memilih username dan menginput password sesuai dengan bagian masing - masing, sehingga hak akses yang dimiliki berbeda. Gambar 10 menunjukkan proses login yang dilakukan oleh bagian Mesin, dan hasil yang ditampilkan ketika berhasil login.

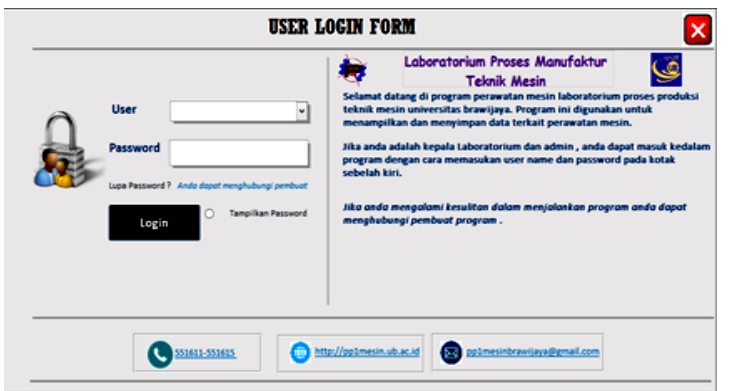

Gambar 10. Printscreen Proses Login Bagian Mesin

2). Gambar 11 merupakan hasil login dari bagian data mesin, terlihat pada master 
data dan menu yang dapat di akses hanya bagian mesin pada master data.

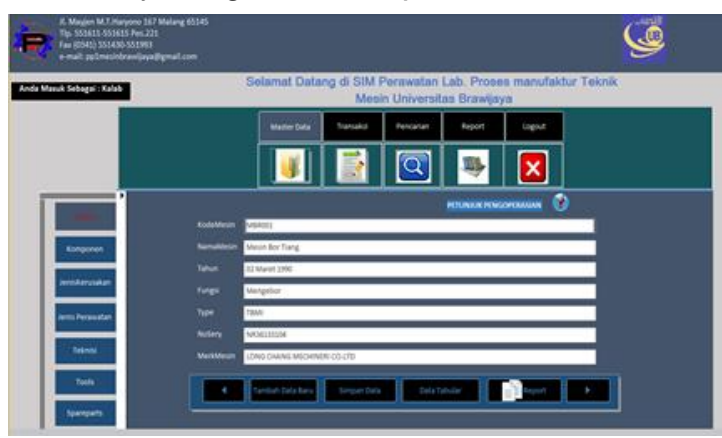

Gambar 11. Printscreen Hasil Login Bagian Mesin

3). Printscreen Hasil Login Bagian Mesin

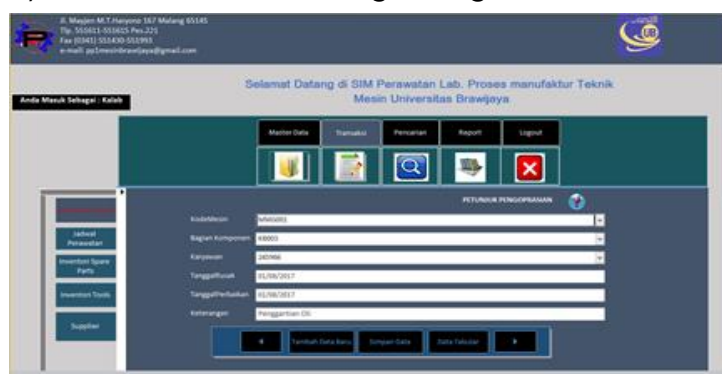

Gambar 12. Printscreen Hasil Login Bagian Mesin

\section{4). Salah Satu Laporan Rekapan}

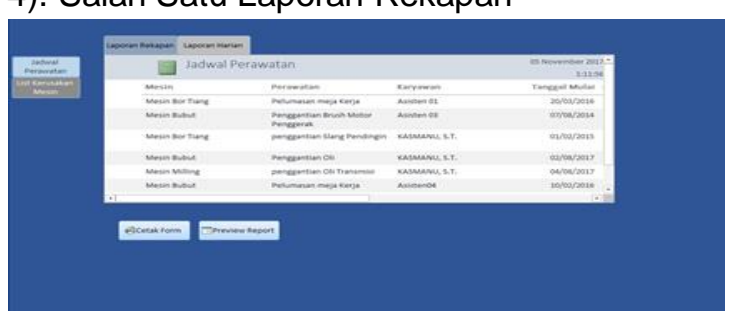

Gambar 13. Laporan Rekapan

5) Menu Proses Pencarian

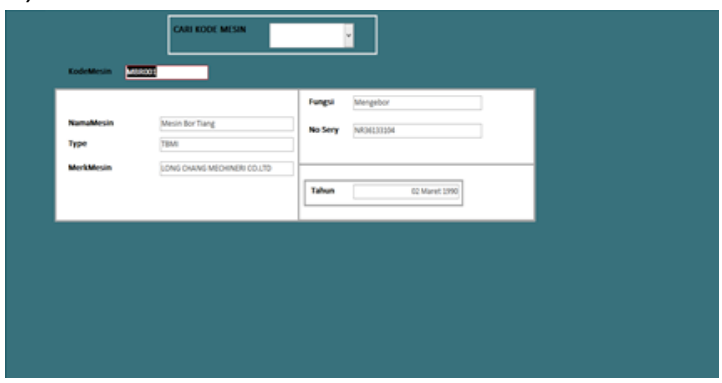

Gambar 14. Menu Pencarian
6) Data Stock dan Peringatan

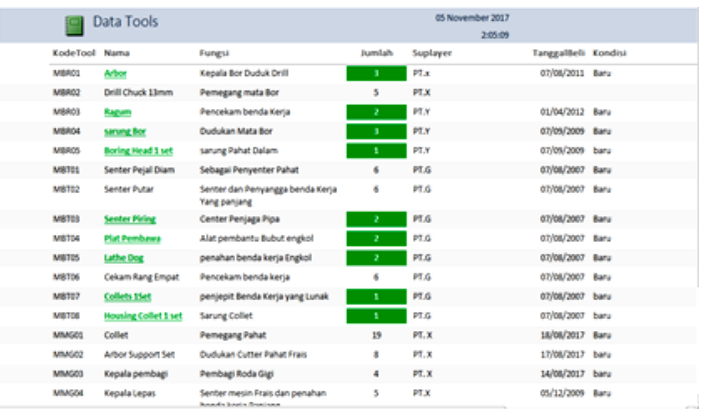

Gambar 15. Data Stock Tools

7.) Menu Peringatan Pada Saat Pertama Masuk Login

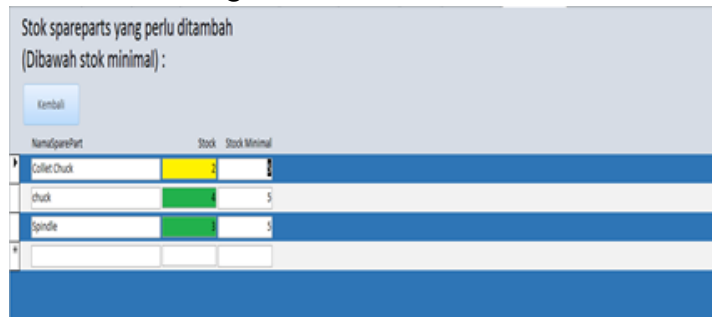

Gambar 16. Menu Peringatan

b. Hasil Uji Validasi

Uji validasi bertujuan untuk menguji apakah sistem yang dirancang dapat berfungsi sepenuhnya dan memenuhi kebutuhan user sebagai sistem informasi yang dapat membantu proses manajemen pearwatan mesin.

Tabel 7. Validasi Sistem Informasi Manajemen Perawatan Mesin

\begin{tabular}{|c|c|}
\hline Pengguna & Kebutuhan Pengguna \\
\hline \multirow{3}{*}{ Kalab } & $\begin{array}{l}\text { Kalab dapat menerima laporan dari } \\
\text { sistem informasi admin dan teknisi/ } \\
\text { pegawai diantaranya laporan } \\
\text { rekapan, laporan harian dan data - } \\
\text { data tambahan misalnya mencari } \\
\text { suplier. }\end{array}$ \\
\hline & $\begin{array}{l}\text { b. Kalab menerima laporan rutin } \\
\text { tentang jadwal perawatan dengan } \\
\text { berisi diantaraya, data mesin, } \\
\text { perawatan, karyawan, tanggal } \\
\text { mulai, tanggal selesai dan durasi. } \\
\text { Atas dasar ini kalab dapat } \\
\text { mengambil keputusan mesin mana } \\
\text { yang harus mendapat perawatan } \\
\text { mingguan, bulanan dan } \\
\text { persemester. }\end{array}$ \\
\hline & $\begin{array}{l}\text { Kalab menerima laporan rutin } \\
\text { tentang jenis kerusakan dengan } \\
\text { berisi, data mesin, bagian } \\
\text { komponen, tanggal kerusakan, jenis }\end{array}$ \\
\hline
\end{tabular}




\begin{tabular}{|c|c|c|}
\hline \multirow[t]{7}{*}{ (1) } & 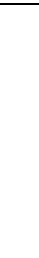 & $\begin{array}{l}\text { kerusakan, bentuk perawatan, kode } \\
\text { karyawan, apakah penggantian } \\
\text { sparepart dan tanggal selesai. } \\
\text { Sehingga dengan adanya data - } \\
\text { data ini maka kalab membuat } \\
\text { keputusan mesin paling banyak } \\
\text { rusak dan paling sering penggantian } \\
\text { sparepart. }\end{array}$ \\
\hline & & $\begin{array}{l}\text { Kalab menerima data laporan } \\
\text { rekapan komponen didalamnya } \\
\text { tentang kode komponen, kode } \\
\text { mesin, nama komponen, tahun, } \\
\text { fungsi dan kondisi.sehingga dengan } \\
\text { data - data ini kalab membuat } \\
\text { keputusan penggantian komponen } \\
\text { mesin perbaikan. }\end{array}$ \\
\hline & & $\begin{array}{l}\text { Kalab menerima laporan rekapan } \\
\text { mesin didalamnya terdapat kode } \\
\text { mesin, nama mesin, tahun, fungsi, } \\
\text { type, no sery dan merk. Atas data - } \\
\text { data ini kalab membuat keputusan } \\
\text { untuk penambahan mesin dan } \\
\text { sparepart. }\end{array}$ \\
\hline & & $\begin{array}{l}\text { Kalab menerima laporan rekapan } \\
\text { data sparepart didalamnya terdapat } \\
\text { kode sparepart, kode komponen, } \\
\text { kode mesin, nama sparepart, stock, } \\
\text { tahun dan fungsi. Atas dasar ini } \\
\text { kalab membuat keputusan untuk } \\
\text { penambahan stock sparepart. }\end{array}$ \\
\hline & & $\begin{array}{l}\text { Kalab menerima laporan rekapan } \\
\text { data teknisi didalamnya terdapat } \\
\text { NIK, nama, nohp, alamat, } \\
\text { pendidikan, keahlian, tanggal lahir } \\
\text { dan TMT. Atas dasar data - data ini } \\
\text { kalab membuat keputusan untuk } \\
\text { membuatkan jadwal perawatan } \\
\text { mesin sesuai dengan keahlian } \\
\text { masing - masing teknisi/pegawai. }\end{array}$ \\
\hline & & $\begin{array}{l}\text { Kalab menerima laporan rekapan } \\
\text { data tools didalamnya terdapat data } \\
\text { kode tools, nama, fungsi, jumlah, } \\
\text { suplayer, tanggal beli, dan kondisi } \\
\text { dan merk. Atas dasar data ini kalab } \\
\text { membuat keputusan pembelian } \\
\text { stock tools dan jumlah stock yang } \\
\text { ada sekarang. }\end{array}$ \\
\hline & & $\begin{array}{l}\text { Kalab memudahkan mendapatkan } \\
\text { data - data didalam laboratorium } \\
\text { proses manufaktu teknik mesin } \\
\text { karna dengan adanya sistem } \\
\text { informasi. }\end{array}$ \\
\hline \multirow{3}{*}{ Admin } & & $\begin{array}{l}\text { Admin dapat memperoleh hasil } \\
\text { report, semua data yang ada di } \\
\text { sistem informasi manajemen } \\
\text { perawatan mesin }\end{array}$ \\
\hline & & $\begin{array}{l}\text { Dapat melihat, mengedit, menginput } \\
\text { data baru dan menambahkan hasil } \\
\text { rekap laporan jadwal perawatan, } \\
\text { jenis kerusakan, jenis perawatan, } \\
\text { kerusakan mesin, komponen, } \\
\text { mesin, sparepart, teknisi, tools, } \\
\text { mencari data - data, melihat data } \\
\text { dan mencetak. }\end{array}$ \\
\hline & & $\begin{array}{l}\text { Sistem mampu memberikan kontrol } \\
\text { terhadap jadwal perawatan yang }\end{array}$ \\
\hline
\end{tabular}

\begin{tabular}{|l|l|}
\hline \multicolumn{1}{|c|}{} & $\begin{array}{l}\text { dilakukan dengan memberikan } \\
\text { peringatan terhadap sparepart dan } \\
\text { tools yang stock berkurang. } \\
\text { Implentasinya di lampiran 12 }\end{array}$ \\
\hline d. $\begin{array}{l}\text { Sistem mampu memberikan laporan } \\
\text { harian dan laporan rekapan kepada } \\
\text { kalab }\end{array}$ & $\begin{array}{l}\text { Sistem dapat memberikan data dari } \\
\text { suplayer agar mudah dalam } \\
\text { pembelian stock sparepart, tools } \\
\text { dan sparepart yang khusus buat } \\
\text { mesin di dalal laboratorium proses } \\
\text { manufaktur. }\end{array}$ \\
\hline f. & $\begin{array}{l}\text { Admin dapat menyimpan data - } \\
\text { data suplier untuk mempermudah } \\
\text { pembelian mesin dan sparepart. }\end{array}$ \\
\hline a. & $\begin{array}{l}\text { Teknisi dapat melihat jadwal } \\
\text { perawatan mesin didalam sistem } \\
\text { informasi }\end{array}$ \\
\hline beknisi & $\begin{array}{l}\text { teknisi dapat melihat diskripsi job } \\
\text { masing }\end{array}$ \\
\hline
\end{tabular}

\section{KESIMPULAN}

Berdasarkan hasil pengujian yang meliputi uji verifikasi, uji validasi dan uji prototype, maka dapat ditarik kesimpulan sebagai berikut :

1. Telah di desain database untuk mendukung manajemen perawatan mesin di Laboratorium Proses Manufaktur yang mengandung file/tabel sebagaai berikut: mesin, tabel jadwal perawatan, jenis kerusakan, jenis perawatan, kerusakan mesin, komponen, sparepart, teknisi dan tools, serta pembuatan prototype sistem informasi dengan menggunakan microsoft access 2016.

2. Atas dasar database diatas, dibangun SIMPEM yang mempunyai kemampuan untuk menghasilkan laporan bersifat: rutin, rekapan, dadakan, dan laporan khusus seperti kerusakan mesin. Atas dasar laporan-laporan ini maka kepala lab dan staff dapat mengambil keputusan yang tepat, cepat dan relevan dalam hal perawatan mesin.

3. Prototipe SIMPEM telah diuji secara verifikasi, validasi dan uji prototipe dengan sukses.

\section{DAFTAR PUSTAKA}

[1] Agus Mulyanto, 2009. Sistem Informasi Konsep dan Aplikasi. Yogyakarta: Pustaka Pelajar

[2] Corder, Anthoni (1988), Teknik Manajemen pemeliharaan, Erlangga , Jakarta. 
[3] Fatta, H. 2007.Analisis dan Perancangan Sistem Informasi untuk Keunggulan Bersaing Perusahaan dan Organisasi Modern. Penerbit Andi. Yogyakarta

[4] Fathansyah, (1999). Sistem Basis Data. Bandung : Penerbit Informatika

[5] Goetsch, David L., Stanley B. Davis, 2000, The Total Quality Approach to Quality Management, 3rd ed., New Jersey: Prentice Hall

[6] McLeod, Raymond, Jr. (2001). Sistem Informasi Manajemen. Jilid I dan Jilid II. PT. Prenhallindo, Jakarta.

[7] Nakajima, S., 1988. "Introduction to Total Productive Maintenance". Produktivity Press Inc, Portland, p 21.

[8] Noraini Hamzah, Zul-Atfi Ismai, Syahrul Nizam Kamaruzzaman, Azrul A. Mutalib, and Adi Irfan Che An. 2016. A CMMS Expert using BIM for IBS Building Maintenance

[9] Supandi, Manajemen perawatan industri. Bandung: Ganeca Exact. 1990

[10] Utami, Ema dan Sukirno. 2003. Konsep Dasar Pengolahan dan Pemprograman Database dengan SQL Server, Ms. Access dan Ms. Visual Basic. Yogyakarta: Andi Publisher

[11] Rajiv Kumar, and P C Tewari.2012. Designing of Computerized Maintenance Management Information System and Root Cause Analysis for National Fertilizers Limited, Panipat, India. Department of Mechanical Engineering, National Institute of Technology, Kurukshetra, Haryana,India.
[12] C.G. Ramachandra, T.R. Srinivas, T.S. Shruthi. 2012. A Study on Development and Implementation of a Computerized Maintenance Management Information System for a Process Industry. International Journal of Engineering and Innovative Technology (IJEIT), Volume 2, Issue 5, ISO 9001:2008 Certified, ISSN: 2277-3754.

[13] Soumava Mandal, and P C Tewari. 2017. A Proposed Framework for Computerized Maintenance Management System for a Power Plant., Department of Mechanical Engineering, NIT Kurukshetra 136119 Haryana, India

[14] Suleiman Abdulrahman, Saleh U.A., F. I Onuigbo. 2017. Application of Information and Communication Technology in Engineering for Effective Maintenance Management. International Journal of Engineering and Applied Sciences (IJEAS), Volume-4, Issue-2, ISSN: 2394 3661

[15] Vinod Kumar, and P C Tewari. 2013. A Proposed Framework of Computerized Maintenance Management Information System for JCB India Limited, Ballabgarh. Department of Mechanical Engineering, NIT Kurukshetra 136119, Haryana, India; and is the corresponding author

[16] Danang Murdiyanto, Pratikto2, Purnomo Budi Santoso. 2016. Rekayasa Sistem Informasi Menajemen Perakitan Berbasis Group Technology Untuk Mendukung Proses Assembly Frame Budy bus, Jurnal Rekayasa Mesin Vol.7, No.2, 75 85. 